\title{
Bangladesh Endocrine Society (BES) Position Statement for Management of Diabetes and Other Endocrine Diseases in Patients with COVID-19
}

\author{
Faruque Pathan' \\ Shahjada Selim (D) ${ }^{2}$ \\ Md Fariduddin ${ }^{2}$ \\ Md Hafizur Rahman ${ }^{3}$ \\ SM Ashrafuzzaman' \\ Faria Afsana' \\ Nazmul Kabir Qureshi $\mathbb{D}^{4}$ \\ Tanjina Hossain $\mathbb{1}^{5}$ \\ M Saifuddin 6 \\ AB Kamrul-Hasan (iD ${ }^{7}$ \\ Ahmed Salam Mir $^{8}$ \\ On behalf of the BES Diabetes \\ and COVID Task Force
}

\footnotetext{
'Department of Endocrinology, BIRDEM General Hospital, Dhaka, Bangladesh; ${ }^{2}$ Department of Endocrinology, Bangabandhu Sheikh Mujib Medical University, Dhaka, Bangladesh; ${ }^{3}$ Bangladesh Endocrine Society, Dhaka, Bangladesh; ${ }^{4}$ National Healthcare Network (NHN) Uttara EC, Dhaka, Bangladesh; ${ }^{5}$ Department of Endocrinology, Green Life Medical College Hospital, Dhaka, Bangladesh; ${ }^{6}$ Department of Endocrinology, Dhaka Medical College Hospital, Dhaka, Bangladesh; ${ }^{7}$ Mymensingh Medical College Hospital, Dhaka, Bangladesh; ${ }^{8}$ Department of Endocrinology, BIHS General Hospital, Dhaka, Bangladesh
}

Background: The year 2020 witnessed a largely unprecedented pandemic of coronavirus disease (COVID-19), caused by SARS COV-2. Many people with COVID-19 have comorbidities, including diabetes, hypertension and cardiovascular diseases, which are significantly associated with worse outcomes. Moreover, COVID-19 itself is allied with deteriorating hyperglycemia. Therefore, Bangladesh Endocrine Society has formulated some practical recommendations for management of diabetes and other endocrine diseases in patients with COVID-19 for use in both primary and specialist care settings.

Objective: The objective of the article is to develop a guideline to protect the vulnerable group with utmost preference - the elderly and those with comorbid conditions. Therefore, to ensure the adequate protective measures and timely treatment for COVID-19 patients with diabetes, other endocrine diseases or any other comorbidities.

Considering and Monitoring Issues:

- The risk of a fatal outcome from COVID-19 may be up to $50 \%$ higher in patients with diabetes than in non-diabetics.

- Patients with diabetes and COVID had CFR 7.3-9.2\%, compared with $0.9-1.4 \%$ in patients without comorbidities.

- Diabetic ketoacidosis may be one of the causes of mortality in COVID-19.

- There is wide fluctuation of blood glucose in these patients, probably due to irregular diet, reduced exercise, increased glucocorticoids secretion, and use of glucocorticoids.

- HbA1c should be $<7.0 \%$ for the majority of the patients, this target may be relaxed in appropriate clinical settings.

- More emphasis should be given on day-to-day blood glucose levels. Hypoglycemia $(<3.9$ mmol/l) must be avoided.

- Frequent monitoring of blood glucose is needed in critically ill patients.

Conclusion: The fight against COVID-19 has been proven to be a challenging one. Therefore, all healthcare personnel should make the best use of updated knowledge and skills to ensure adequate protective measures and timely treatment for COVID-19 patients with diabetes, other endocrine diseases or any other comorbidities.

Keywords: COVID-19, diabetes mellitus, SARS COV-2, antidiabetic medications, endocrine diseases and COVID-19, thyroid disease and COVID-19

\section{Preamble}

The purpose of guidelines and recommendations is to summarize and assess available evidence to help healthcare professionals in appropriate decision making in the management of an individual patient with a given condition. The Bangladesh Endocrine Society (BES), as a professional body, has been publishing its recommendations for the last few years. In response to the global COVID-19 pandemic, BES formed a task force comprising experts in this field to formulate practical
Correspondence: Shahjada Selim Department of Endocrinology, Bangabandhu Sheikh Mujib Medical University, Shahbagh, Dhaka, 1000, Bangladesh

Email selimshahjada@yahoo.com 
recommendations for the management of patients with diabetes mellitus and/or other endocrine disorders with COVID-19. The members of this task force comprehensively reviewed the available evidence for the specific conditions. Search engines such as Google Scholar, PubMed and Scopus were used, with keywords including

COVID-19 and Diabetes Mellitus, SARS COV-2, Antidiabetic Medications, Endocrine diseases and COVID-19, Thyroid disease and COVID-19, Adrenal disease and COVID-19, Pituitary disease and COVID-19.

Each section of the recommendation was drafted by one member, followed by rigorous review and modifications by other members. During selection of the articles, interventional studies were given highest preference, but due to the scarcity of sufficient randomized trials in this field, observational studies, case studies and expert recommendations were also included. Therefore, this recommendation is a combination of expert opinions and narrative summary of the available evidence regarding management of COVID-19 patients with diabetes mellitus and/or other endocrine diseases.

\section{Introduction}

The year 2020 witnessed a largely unprecedented pandemic of coronavirus disease (COVID-19), caused by SARS COV-2. Many people with COVID-19 have comorbidities, including diabetes, hypertension and cardiovascular diseases, which are significantly associated with worse outcomes. ${ }^{1}$ Moreover, COVID-19 itself is associated with worsening of hyperglycemia. Depending on the global region, 20-59\% patients in the COVID-19 pandemic had diabetes. ${ }^{2}$ In Bangladesh, one in every 12 adults has diabetes, with a prevalence of $8.4 \% .^{3}$ Data suggest that only $22.5 \%$ of patients with diabetes have good glycemic control. ${ }^{3}$ Therefore, the Bangladesh Endocrine Society has formulated some practical recommendations for management of diabetes and other endocrine diseases in patients with COVID-19 for use in both primary and specialist care settings.

\section{Diabetes and COVID-19}

The risk of a fatal outcome from COVID-19 may be up to $178-221 \%$ higher in patients with diabetes than in nondiabetics. $^{4-6}$ Data show that patients with diabetes and COVID had CFR 7.3-9.2\%, compared with $0.9-1.4 \%$ in patients without comorbidities. ${ }^{7,8}$ Diabetic ketoacidosis may be one of the causes of mortality in COVID-19. ${ }^{9}$
There is wide fluctuation of blood glucose in these patients, probably due to irregular diet, reduced exercise, increased glucocorticoids secretion, use of glucocorticoids etc. Also, COVID-19 can induce a large number of inflammatory cytokines leading to severe insulin resistance. ${ }^{10}$ The reason behind increased severity of COVID-19 in diabetes is complex. Gupta et al. noted that poor glycemic control impairs several aspects of the immune response to viral infections. Inappropriate T-cell action, impaired NK cell activity and defects in complement action can reduce viral clearance. Diabetes and obesity are associated with abnormal secretion of adipokines and cytokines such as TNF- $\alpha$ and interferon, predisposing to severe infection. Plasminogen is increased in diabetes, increasing the virulence of SARS CoV-2. ${ }^{11}$ Higher levels of IL-6, ESR, CRP, ferritin, fibrinogen and D-dimer were reported in patients with diabetes compared with nondiabetics. ${ }^{12}$ Furin, a membrane bound protease involved in the entry of coronaviruses into the cell, is increased in diabetes, which may promote viral replication. Comorbidities such as hypertension, CAD and CKD further worsen the prognosis. $^{11}$ Figure 1 shows a summary of postulated mechanisms of increased severity of COVID-19 in diabetic patients.

Angiotensin-converting-enzyme 2 (ACE2) has been identified as the receptor for the coronavirus spike protein. COVID-19 infection decreases ACE2 expression, increasing the risk of cellular damage, hyperinflammation and respiratory failure. ${ }^{13}$ Chronic hyperglycemia downregulates ACE2 expression making the cells vulnerable to the inflammatory effect of the virus. But acute hyperglycemia upregulates ACE2 expression, facilitating viral cell entry. It is also postulated that COVID-19 can induce new onset diabetes via its direct effect on pancreatic $\beta$ cells which express ACE2 receptors. ${ }^{14-16}$

\section{Glycemic Targets and Glucose Monitoring} HbAlc should be $<7.0 \%$ for the majority of the patients, this target may be relaxed in appropriate clinical settings. ${ }^{17}$ More emphasis should be given on day-to-day blood glucose levels. Hypoglycemia $(<3.9 \mathrm{mmol} / \mathrm{l})$ must be avoided (Table 1). ${ }^{17,18}$

In the case of continuous glucose monitoring/flash glucose monitoring, time-in-range (3.9-10.0 $\mathrm{mmol} / \mathrm{l}$, $70-180 \mathrm{mg} / \mathrm{dL}$ ) should be $>70 \%$ of the time (or $>50 \%$ in frail and older people and moderate to severe cases). ${ }^{2}$ For severe and critically ill patients who are on intravenous insulin infusion, the glycemic target should be 7.8-10 $\mathrm{mmol} / \mathrm{L}(140-180 \mathrm{mg} / \mathrm{dL})$. 


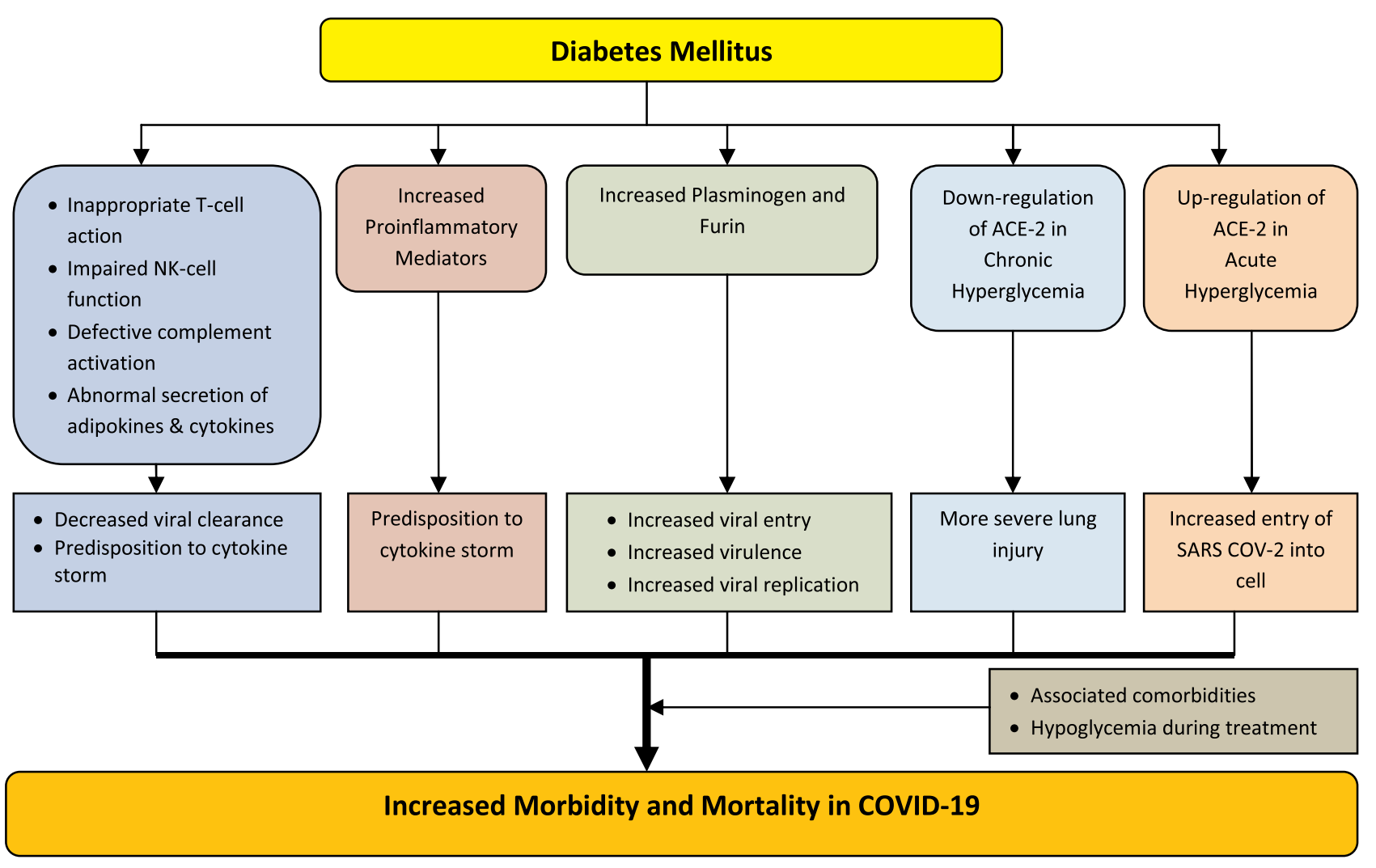

Figure I Suggested mechanisms of increased severity of COVID-19 in diabetes.

\section{Glucose Monitoring}

Self-monitoring of blood glucose (SMBG) is an acceptable alternative to laboratory plasma glucose estimation in the present scenario. SMBG should be checked at any clinical suspicion of hypoglycemia. ${ }^{19-21}$ Frequent monitoring of blood glucose (every hour or every $2 \mathrm{~h}$ ) is needed in patients with very poor oral intake or those in ICU or nonICU who are on mechanical ventilation who would require intravenous insulin infusion. ${ }^{19-21}$ Table 2 shows the recommended frequency of SMBG in COVID patients.

Continuous glucose monitoring (CGM) may confer additional benefit in terms of glycemic control in patients receiving multiple dose insulin injections, continuous subcutaneous insulin infusion (CSII) or insulin pump or intravenous insulin syringe pump. ${ }^{19-22}$

\section{Nutrition Management and Physical Activity in COVID-19 and Diabetes}

Some conditions may interfere with a healthy regular diet, such as anorexia and anosmia, gastrointestinal symptoms such as diarrhea, vomiting, dehydration, irregular schedule, lack of care in isolation ward, stress, anxiety, insomnia etc. ${ }^{23}$ During sick days, the patient should follow the regular calorie and schedule given before. To maintain hydration at least half a cup $(100 \mathrm{~mL})$ of water or unsweetened drinks should be taken hourly. The patient should not miss meals and should not fast. If unable to eat much, he/she should try snacks or drinks with carbohydrates. A regular meal schedule should be maintained. Glucose

Table I Plasma Glucose Targets

\begin{tabular}{|l|c|c|c|}
\hline & $\begin{array}{c}\text { Strict Control (Mild } \\
\text { and Moderate IIIness } \\
\text { in Young) }\end{array}$ & $\begin{array}{c}\text { Medium Control (Mild and Moderate IIIness } \\
\text { in Elderly, or Patients on Glucocorticoids and } \\
\text { in Resource-Poor Inpatient Care Settings) }\end{array}$ & $\begin{array}{c}\text { Low Control (Severe IIIness, Hypoglycemia } \\
\text { Intolerable Patients, or Patients Having } \\
\text { Organ Dysfunctions or Serious } \\
\text { Cardiovascular or Cerebrovascular Diseases) }\end{array}$ \\
\hline $\begin{array}{l}\text { Fasting (mmol/L) } \\
2 \mathrm{~h} \text { post-prandial (mmol/L) }\end{array}$ & $\begin{array}{c}4.4-6.1(80-110 \mathrm{mg} / \mathrm{dL}) \\
6.1-7.8(110-140 \mathrm{mg} / \mathrm{dL})\end{array}$ & $6.1-7.8(110-140 \mathrm{mg} / \mathrm{dL})$ & $7.8-10.0(140-180 \mathrm{mg} / \mathrm{dL})$ \\
$7.8-10.0(140-180 \mathrm{mg} / \mathrm{dL})$ & $7.9(140-250 \mathrm{mg} / \mathrm{dL})$ \\
\hline
\end{tabular}

Note: Data from Cemiyeti. ${ }^{18}$ 
Table 2 SMBG Frequency

\begin{tabular}{|l|l|l|}
\hline $\begin{array}{l}\text { Type of } \\
\text { Diabetes }\end{array}$ & Patient Category & Recommended Frequency of SMBG \\
\hline Type 2 DM & $\begin{array}{l}\text { On Sulphonylureas or } \\
\text { Meglitinides } \\
\text { On other OADs } \\
\text { On Insulin } \pm \text { OADs }\end{array}$ & $\begin{array}{l}\text { - Four times/day and should include preprandial, post-prandial and bedtime levels. } \\
\text { - In well-controlled diabetes, daily fasting and after the major meal may be justified. } \\
\text { - Fasting and post-prandial capillary blood glucose once or twice a week. } \\
\text { - At least } 4 \text { times/day and should include preprandial, post-prandial and bedtime levels. }\end{array}$ \\
\hline $\begin{array}{l}\text { Diabetes in } \\
\text { pregnancy }\end{array}$ & On lifestyle modifications & $\begin{array}{l}\text { - A day profile once a week FBG and } 3 \text { post-prandial values at least once a week or staggered } \\
\text { over the week. }\end{array}$ \\
\cline { 2 - 3 } & On insulin & - At least 4 times/day (FBG and 3 post-prandial values). \\
\hline Type I DM & $\begin{array}{l}\text { On multiple dose insulin } \\
\text { injection }\end{array}$ & Pre- and post-meals, at bedtime, at 3am (if nocturnal hypoglycemia). \\
\hline
\end{tabular}

Note: Data from Banerjee et al, ${ }^{19}$ Basu et $a l,{ }^{20}$ and Rao et al. ${ }^{21}$ Abbreviations: OAD, oral antidiabetic drug; FBG, fasting blood glucose.

drink or lozenge or tablet should be kept with the patient in their isolation room or ward. Plenty of fruits and vegetables, at least 2 or 3 servings a day, should be taken. If the patient is unable to eat due to vomiting or cannot remain hydrated, then urgent medical help is needed. ${ }^{24,25}$ Enough lean protein such as fish, meat, egg, milk, cheese, seeds or nuts should be consumed. Protein restrictions $(0.8 \mathrm{~g}$ per $\mathrm{kg}$ body weight) may be needed in chronic kidney disease with diabetes. ${ }^{26}$ In critical, intubated or ventilated ICU patients with COVID-19, enteral nutrition (EN) should be started through a nasogastric tube. Isocaloric nutrition rather than hypocaloric nutrition can be increasingly implemented after the early stage of acute illness. Blood glucose should be continued at target levels with monitoring of blood triglycerides and electrolytes including phosphate, potassium and magnesium. ${ }^{26}$ There are recommendations for the population to take vitamin D supplements during this pandemic. ${ }^{27}$ Zinc has been shown to have inhibitory effects on $\mathrm{H}_{1} \mathrm{~N}_{1}$ viral load, but any effect in COVID-19 is unknown. ${ }^{28}$ Vitamin C supplementation has some role in prevention of pneumonia and its effect in COVID-19 needs evaluation. ${ }^{29}$ During sick days, vigorous exercise is not advised. If the disease category is mild some home exercises can be done. Breathing exercises and maintaining a prone position is beneficial. The patient should walk for a few steps or move their legs every 2 hours to prevent thromboembolism. Specialist respiratory physiotherapists may be needed in hospitals and ICU setting. Enough sleep is necessary. ${ }^{30-32}$

\section{Home Management, Indications for Hospital Care and Sick Day Rules Rules for DM Patients with COVID-I9 Infection}

At home, the patient should remain isolated in a single room, use a single toilet, should practice hand washing with soap-water 20 seconds each time frequently or before/after taking meal or after using washroom, after coughing, sneezing. A $60 \%$ alcohol-based sanitizer can be used. Cough/sneezing etiquette can be maintained by using tissue paper, cloth or elbow/hand. Face mask should be used. Care should be given by a single healthy person maintaining protective measures. Home floor, furniture, door knobs, light switch, sink, toilet seat, handles should be cleaned and disinfected after use. Meditation, prayer can help in minimizing stress and anxiety. News that can cause distress or anxiety should be minimized. Regular sleep is essential. Contact with relatives, friends and neighbors via telephone, online communication can be practiced to reduce effects of social isolation. Supply/storage of prescribed anti-diabetic medications/refills at home should be ensured for one to three months. ${ }^{33-36}$

Table 3 shows the proposed indications of hospitalization in diabetic patients with COVID-19.

Rules for DM Patients to Prevent Exposure to COVID-19 People with DM should stay at home as much as possible to reduce exposure risk. If it is necessary to go out, crowds should be avoided, social distancing should be maintained by 1-2 meters and a face mask should be used. Routine clinic visits can be minimized while telemedicine/ video consultations, telephone advice, online drug delivery 
Table 3 Indications of Hospitalization vs Home Management in Diabetic Patients with COVID-19

\begin{tabular}{|l|l|}
\hline \multicolumn{2}{|l|}{ Diabetes Mellitus with COVID-19 Disease } \\
\hline Who Can Be Treated at Home' & Indication for Hospitalization ${ }^{33,34}$ \\
\hline - Mild COVID-19 cases having uncomplicated upper & - Blood glucose $>15 \mathrm{mmol} / \mathrm{l}(>270 \mathrm{mg} / \mathrm{dL}$ ) on repeated measurements. \\
$\begin{array}{l}\text { respiratory tract infection with non-specific symp- } \\
\text { toms (such as fever, fatigue, cough with or without }\end{array}$ & - Ketones in urine. \\
sputum, sore throat, nasal congestion, anorexia, & - Excessive thirst. \\
malaise, or headache). & - Unable to take food and drinks for 6 hours. \\
& - Weight loss of $\geq 2.5 \mathrm{~kg}$ during the illness. \\
& - Rapid breathing. \\
& - Abdominal pain. \\
& - Reduced level of consciousness (drowsiness). \\
& - Co-existing serious morbidities. \\
& - Clinical feature of moderate, severe and critical Covid- 19 cases \\
\hline
\end{tabular}

should be considered. Non-emergency routine evaluations should be deferred. Storage of medications and glucose testing kit should be ensured for 1-3 months. With routine SMBG, medication should be adjusted. Home-based exercise like treadmill, stationary cycling, free hand or aerobics, walking in room, roof, parking area or climbing stairs can be done. Diet with plenty of vegetables and citrus foods should be consumed. Hand hygiene should be maintained as mentioned in previous section. When coughing or sneezing, people with DM should cover nose and mouth with a tissue or a flexed elbow. They should avoid touching eyes, mouth or nose and should avoid meeting sick individuals, unprotected contact with wildlife and farm animals, sharing food, tools, glasses, towels. Vaccination to prevent secondary infection (e.g. influenza, streptococcal pneumonia) should be considered. $^{33-35}$

\section{General Rules During Sickness}

Fluid intake should be carefully balanced with vomiting or diarrhea if any. The patient should take plenty of water or calorie-free drinks at $120-180 \mathrm{~mL}$ per hour to avoid dehydration and if they cannot take $50 \mathrm{~g}$ of carbohydrates through food, it might also be necessary to drink sugary beverages while monitoring SMBG to avoid hyperglycemia. Weight should be measured every day; losing weight can be a sign of high blood glucose. The patient should have daily foot checks to ensure early detection of poor blood supply or infection. . $^{30,34,37}$

\section{Treatment of DM in COVID-19:} Anti-Diabetic Agents: Oral and Parenteral Type 2 diabetes treatment in COVID-19 patients with oral or parental glucose lowering drugs depends on clinical severity of illness and associated comorbid situations. Regarding use of antidiabetic agents, there are many controversies and misconceptions during the COVID-19 pandemic. There are also recent recommendations from different authors, experts and organizations. Considering all these, this recommendation is made from the Bangladesh Endocrine Society.

\section{Considerations to Use Anti-Diabetic Drugs}

Metformin is the widely used first-line antidiabetic agent for management of type 2 diabetes mellitus. It is responsible for the activation of the AMP-activated protein kinase (AMPK) in the liver and thereby decreases hepatic glucose output. ${ }^{38}$ The activation of AMPK by metformin also leads to phosphorylation of ACE2 which can lead to conformational and functional changes to this receptor. ${ }^{39}$ Activation of ACE2 increases its protective anti-inflammatory activity which may prevent hyperinflammation in COVID-19 infection. ${ }^{40}$ Metformin also has anticipated antiproliferative and immunomodulatory effects due to activation of AMPK and has shown to have a protective role in pneumonia in mouse model and decreased mortality in sepsis, tuberculosis and COPD in previous human studies. ${ }^{41}$ Meanwhile, several studies have reported the outcomes of metformin use in patients with type 2 diabetes with COVID-19. Although one study reported an increase in severity of infection with metformin use, some studies found neither harm nor benefit both in severity and mortality, but the majority reported a significant reduction in mortality. ${ }^{42}$ Metformin also has an indirect effect to decrease replication of this virus. ${ }^{43}$ Considering all these, although there are no recent good data in COVID-19, metformin may be a real game changer in COVID-19 pandemic. ${ }^{40}$ It is evident that lactic acidosis 
with metformin use is a rare event and predictable only in severe or critical COVID 19 illness with hypoxia or renal dysfunction. ${ }^{2,41}$ Beside a major role in carbohydrate metabolism, DPP4 enzyme also plays an important role in immune regulation, but this is not completely understood. DPP4 activates T cells and upregulates CD86 expression and NF$\kappa \mathrm{B}$ pathway and increases inflammation in type 2 diabetes. So, DPP4 may represent a potential target for preventing and reducing the risk and progression of the acute respiratory complications of COVID-19 infection in type 2 diabetes. ${ }^{44}$ A meta-analysis has shown that upper respiratory tract infections do not increase significantly with DPP4 inhibitor treatment. ${ }^{45}$ DPP4 inhibitors have shown anti-inflammatory effects. $^{44}$ In COVID-19 disease, there can be a cytokine storm and excessive inflammatory response. So exploiting the defending role of DPP-4 inhibitors in decreasing the profound inflammation seems logical. Although available data suggest that DPP4 inhibitors produce no harm, a relatively large study shows that there is emerging evidence that it may lower the risk of severe COVID-19. ${ }^{46}$ Recently, it has been hypothesized that SGLT-2i, GLP-1RAs and pioglitazone might induce an over-expression of the ACE2 receptor, which may have more serious consequences if a diabetic patient is infected. ${ }^{47,48}$ GLP-1RA has shown over the years a significant anti-inflammatory and anti-adipogenic effect. ${ }^{49}$ Similar evidence of anti-inflammatory effect is also seen with SGLT-2i and pioglitazone. ${ }^{50,51}$ Although there is increased chance of COVID-19 infection through ACE2 overexpression, pioglitazone also reduces proinflammatory cytokines and inflammatory markers, and cytokine storm and fibrotic lung damage. ${ }^{41}$ The usefulness of both GLP-1Ra and SGLT-2 $i$ for the prevention of cardiovascular and kidney disease is well known. With COVID-19, people with the presence of a cardiovascular or kidney disease show a worse prognosis. ${ }^{52,53}$ Therefore, it seems to be mandatory to preserve the integrity of kidney and of the cardiovascular system in people who could be affected by SARS-CoV-2. ${ }^{48}$ Also euglycemic or moderate hyperglycemic DKA with SGLT-2i are rare events and predictable only in severe or critical COVID 19 illness and especially in a background of poor food intake, dehydration and hypovolemia. ${ }^{2,41}$ Insulin is the most potent, appropriate and safest antidiabetic agent in any acute infection. Although there are claims and counter claims regarding ACE2 overexpression with insulin in COVID-19, multiple stresses including respiratory failure and sepsis in severe COVID-19 infection lead to defects in insulin secretion and action. So, most patients will require insulin in high dose during this infection. ${ }^{2}$
Tables 4 and 5 summarize the recommendations for use of anti-diabetic agents and drugs used for other comorbidities in diabetic patients with COVID-19. Table 6 summarizes the recommendations for management of diabetes according to severity.

Follow BES Insulin Guideline for insulin initiation and intensification (section 3). ${ }^{56}$

Regarding use of investigational anti-COVID-19 drugs (e.g., hydroxychloroquine), consider their glycemic effects. ${ }^{10}$

\section{Diabetes Management in COVID-19 Patients in Hospital Setting}

COVID-19 disease is a challenge for diabetic patients. Presence of diabetes increases disease severity and mortality in COVID-19 patients. Glycemic control needs to be optimal during this pandemic situation. Diabetes management in hospital setup both in outpatient department (OPD) and inpatient needs attention. Access of diabetes patients to outpatient clinics is limited during this pandemic and this urges alternative treatment options, particularly the implementation of telemedicine services. In spite of this situation there will be a few required OPD visits and these can be prioritized as follows.

Table 4 Recommendations for Anti-Diabetic Agents

\begin{tabular}{|l|l|}
\hline Therapy & Suggestions for Practice \\
\hline Metformin & $\begin{array}{l}\text { Continue in mild to moderate COVID-19. Stop if } \\
\text { severely or critically ill or contraindications like renal } \\
\text { failure/hypoxia/acute Gl symptoms/dehydration }\end{array}$ \\
\hline Sulfonylureas & $\begin{array}{l}\text { Continue, adjust dose according to glycemic state, } \\
\text { stop if unable to maintain regular oral food intake or } \\
\text { at risk of hypoglycemia or if insulin is started or if } \\
\text { severely/critically ill }\end{array}$ \\
\hline $\begin{array}{l}\text { SGLT2 } \\
\text { inhibitors }\end{array}$ & $\begin{array}{l}\text { Stop if hospitalized with acute illness/severely or } \\
\text { critically ill/acute Gl symptoms/dehydration }\end{array}$ \\
\hline GLP-IRAs & $\begin{array}{l}\text { Continue in mild to moderate COVID-19 but stop if } \\
\text { acute Gl symptoms/dehydration }\end{array}$ \\
\hline DPP4 & $\begin{array}{l}\text { Continue in mild to moderate COVID-19. Avoid in } \\
\text { severe/critical cases }\end{array}$ \\
\hline inhibitors & $\begin{array}{l}\text { Continue in mild to moderate COVID-19. Use } \\
\text { cautiously where volume overload. Stop if severely/ } \\
\text { critically ill with hemodynamic instability, and hepatic } \\
\text { and cardiac dysfunction }\end{array}$ \\
\hline Pioglitazone \\
\hline Insulin & $\begin{array}{l}\text { gontinue at any stage, adjust dose according to } \\
\text { glyce, often require high dose }\end{array}$ \\
\hline
\end{tabular}

Note: Data from Bornstein et al, ${ }^{2}$ Singh and Khunti, ${ }^{41}$ Singh et al, ${ }^{42}$ Ceriello, ${ }^{51}$ Royal Australian College of General Practitioners, ${ }^{54}$ and Ceriello et al. ${ }^{55}$ 
Table 5 Recommendations for Drugs Used for CoMorbid Diseases of Diabetes

\begin{tabular}{|l|l|l|}
\hline Therapy & Considerations for Use During COVID-19 & $\begin{array}{l}\text { Suggestions for } \\
\text { Practice }\end{array}$ \\
\hline ACEI/ARBs & $\begin{array}{l}\text { - Uncertain risk/benefit - ACEi and ARB could increase the expression of ACE2, which could } \\
\text { accelerate the entry of the virus into the cells, but on the other hand also increase protective anti- } \\
\text { inflammatory effect which could protect against severe lung injury }\end{array}$ & $\begin{array}{l}\text { Continue unless specific } \\
\text { contraindications }\end{array}$ \\
\hline Statins & $\begin{array}{l}\text { - Restore the reduction of ACE2 induced by high lipids such as LDL or lipoprotein(a) } \\
\text { - Have anti-inflammatory effects probably due to the upregulation of ACE2 } \\
\text { - Possibility of increased risk of myositis with experimental antiviral agents/macrolides }\end{array}$ & Continue but monitor risk \\
\hline
\end{tabular}

Note:Data from Ceriello et al ${ }^{48}$ and Royal Australian College of General Practitioners. ${ }^{54}$

Table 6 Recommendations for Management of Diabetes According to Severity

\begin{tabular}{|l|l|}
\hline $\begin{array}{l}\text { Severity of } \\
\text { COVID-19 }\end{array}$ & Treatment Regimen \\
\hline Mild & $\begin{array}{l}\text { Continue current treatment of oral antidiabetic agents (OAD) and/or insulin/GLPI-agonists. Monitor BG frequently and } \\
\text { adjust regimen accordingly }\end{array}$ \\
\hline Moderate & $\begin{array}{l}\text { (a) Continue current treatment regimen if appetite is normal, patient can take food regularly and blood glucose is controlled } \\
\text { (b) If patient cannot eat regularly or blood glucose is high } \\
\text {-If on OAD/Premixed insulin/GLPI-agonists } \rightarrow \text { switch to Basal- bolus/Split-mix SC insulin or IV insulin and adjust dose } \\
\text { according to blood glucose profile. TDD premixed insulin is converted to same TDD of Split-mix/Basal-bolus insulin }\end{array}$ \\
\hline Severe and Critical & $\begin{array}{l}\text { IV insulin should be the Ist line treatment, but SC insulin may be used in severe case, especially if insulin pump is not } \\
\text { available }\end{array}$ \\
\hline On steroid & $\begin{array}{l}\text { Long acting insulin/NPH - I0-20 U once/two divided doses daily and add rapid/short acting insulin subsequently depending } \\
\text { on blood glucose. }\end{array}$ \\
\hline
\end{tabular}

Note:Data from Alshaikh et al. ${ }^{10}$

\section{Outpatient Appointment Prioritization for Specialist Diabetes Departments During the Coronavirus Pandemic}

Urgent face to face appointment is needed in cases of newly diagnosed type 1 diabetes, ${ }^{2,57,58}$ severe hyperglycemia requiring insulin initiation, teaching blood glucose monitoring in an urgent situation such as pregnancy or education about CGM, when blood test monitoring is needed (as in declining renal function or electrolyte imbalance), and if urgent physical examination is required (such as in pregnancy emergencies and severe foot infection). Virtual consultations i.e. telephone, video, email are recommended for follow up of newly diagnosed type $1 \mathrm{DM}$, vulnerable patients for example with history of recent hospital admission, recurrent severe hypoglycemia, $\mathrm{HbA}_{1 \mathrm{c}}>11 \%$ and for diabetes follow up and insulin dose adjustment in pregnancy. Appointment should be deferred in stable and well managed DM, if risk of attending OPD is greater than benefit, and for health education sessions.

\section{Patients Requiring Hospital Admission}

Intravenous insulin is rational for most general surgical and medical patients outside the ICU. Insulin analogues usually produce a lower incidence of hypoglycaemia than do regular human or Neutral Protamine Hagedorn (NPH) insulin. This is preferred treatment for non-critically ill hospitalized patients' basal insulin and a basal plus bolus correction insulin regimen is the preferred treatment with poor oral intake or those who are taking nothing by mouth. An insulin regimen with basal, prandial, and correction components is the preferred treatment for non-critically ill hospitalized patients with good nutritional intake and also for patients requiring glucocorticoid. Only gliding scale insulin use regimen in the inpatient hospital setting is strongly discouraged. If analogue insulin is unaffordable, conventional insulin can be continued being careful about more hypoglycemia while frequent monitoring is necessary. For management of diabetes in hospital setting, DKA and HHS, please refer to BES Insulin Guideline, Sections 
4 and $5 .^{56}$ After the patient improves from the critical illness, when discontinuing intravenous insulin, a transition protocol is recommended. A patient transitioned to a intravenous regimen should receive a dose of subcutaneous basal insulin $2-4 \mathrm{~h}$ before the intravenous infusion is discontinued. For more details, please follow BES Insulin Guideline Section 4. ${ }^{56}$

\section{Diabetes Management After Recovery from COVID-19}

\section{Advice at Discharge from Hospital}

During home isolation for diabetes management the patient should start the drugs according to the advice ${ }^{33}$ of the discharge certificate. They should do SMBG 4 times per day in initial days and contact endocrinologist/diabetologist as soon possible. The endocrinologist/diabetologist will modify, if needed, the management plan gradually to achieve usual glycemic target of the patient. Insulin may be continued, if started during hospital. For the patients who were on insulin prior to hospital stay, they will continue it. When they feel well, they should start physical exercise. The patients should stop smoking, try to reduce body weight, if overweight or obese, check BP at home and be vaccinated for influenza and pneumonia, if not done as per schedule. After discharge from hospital, COVID-19 patients with diabetes should maintain home isolation for at least 3 weeks.

Table 7 Precautions to Prevent COVID-19 in People with Diabetes

General Precautions for COVID Prevention:

- Hand hygiene

- Respiratory hygiene

- Social and physical distancing

- Avoid non-essential travels

Specific Precautions for Diabetic Patients During COVID Pandemic:

- Frequent BG monitoring

- Good glycemic control

- Stabilize cardiac \& renal status (control BP and lipid, stop smoking)

- Proper nutrition

- Regular exercise

- Vaccinate if not taken previously* (e.g., influenza, pneumococcus)

Note: *Patients with diabetes should be vaccinated against COVID-19 complying with national policies.

\section{Prevention of COVID-19 in People with Diabetes}

General precautions are mandatory for patients and caregivers, to prevent contracting COVID-19 ${ }^{59}$ (Table 7).

\section{Pregnancy and Diabetes}

Pregnant women experience immunological and physiological changes according to the $\mathrm{CDC}$ which might make them more susceptible to viral respiratory infections, including COVID-19.

\section{Pre-Existing Diabetes}

Women with pre-existing diabetes have been identified as being more vulnerable to the severe ${ }^{60}$ effects of COVID19. Additional tests at antenatal visit should include $\mathrm{HbA}_{1 \mathrm{c}}$, renal and thyroid function, and urinary albumincreatinine ratio (ACR) and fundoscopy where possible. Face-to-face review is needed if early, this should coincide with the 11-14-week scan. All women with preexisting diabetes should be educated about SMBG, diet chart and sick day rules, information on hypoglycemia avoidance, prescription for folic acid and aspirin. Close and regular phone or email communication between obstetric and diabetic teams is essential to plan care and follow up. Women affected by COVID-19 should be advised to more frequent review of SMBG report.

\section{Gestational Diabetes}

\section{Screening}

In view of the prolonged waiting period in hospital, ${ }^{61} 2$-hour oral glucose tolerance test (OGTT) may be postponed in this COVID 19 situation. For women having high risk of GDM the following modifications (as per Figure 2) could be used.

All women diagnosed with GDM should have an appointment with the diabetes team who will provide glucometer training and diet advice. Where feasible, this should be done via video call. Further diabetes follow up should be done remotely. For GDM women having target glycemic control on diet only, no further hospital visits for diabetes test are needed. They will contact with diabetes team if they have $>3$ abnormal blood glucose levels/week or $>10-15 \%$ of all readings. Postpartum screening for maternal dysglycemia should be deferred until after the COVID-19 pandemic is over.

\section{Health Care Professional (HCP) and Diabetes}

Health-care professionals with diabetes and those with age $>60$ years should be deployed away from front-line clinical duties 


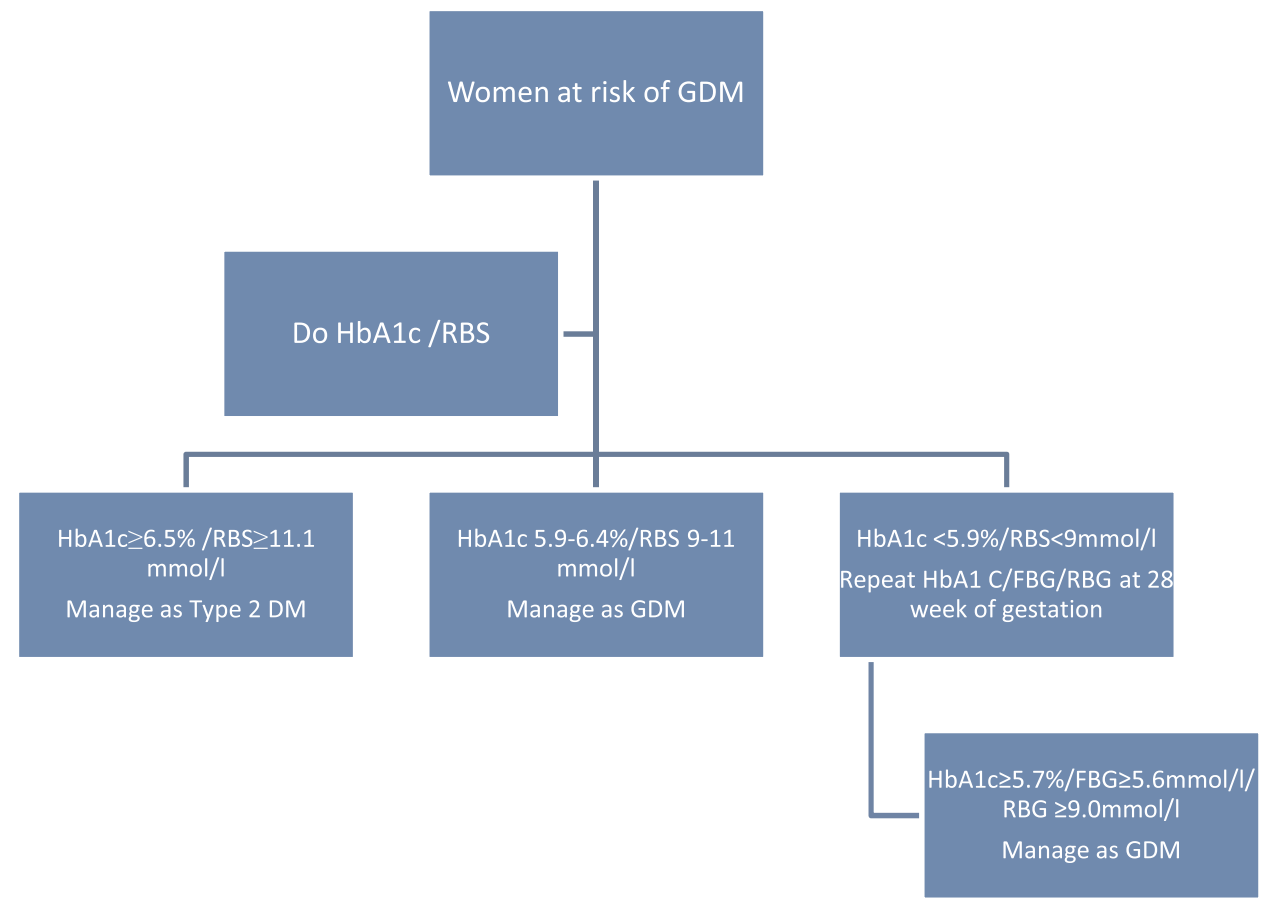

Figure 2 Screening for women with risk factors for GDM. Note:Data from Ceriello et al. ${ }^{55}$

where possible. ${ }^{2}$ For cases in which this is not possible or desirable, high-grade protection or increased protection should be used. ${ }^{2}$ All healthcare personnel should adhere to standard precautions when caring for patients with SARS-CoV-2 infection, using respirator face mask, isolation gown, face shield or goggles, and performing hand hygiene before putting on gloves. ${ }^{62}$ SARS-CoV-2 infection patients whether confirmed or possible should wear a facemask when being evaluated medically. ${ }^{62}$ Any HCP who develops fever or symptoms consistent with COVID 19 should immediately self-isolate and contact to arrange for medical evaluation and testing. ${ }^{62}$

\section{Management of Endocrine Diseases During COVID-19 Pandemic \\ Adrenal Insufficiency}

Individuals with adrenal insufficiency have an increased rate of respiratory infection-related deaths, possibly due to impaired immune function reported in studies. ${ }^{63}$ After diagnosis of COVID-19, a prompt modification of the replacement dose as indicated for the "Sick days" should be established when minor symptoms appear. In general, patients should double their usual glucocorticoid dose to avoid adrenal crisis. Additionally, patients are also recommended to have sufficient stock at home of steroid pills and injections, ideally a 90 -day preparation. ${ }^{63}$ In case of inability to take oral glucocorticoids due to vomiting/diarrhea, injectable steroids should be initiated and hospital admission should be advised. ${ }^{64}$ If adrenal crisis is suspected (fever, hypotension), 100-200 mg hydrocortisone IV 4-6 hourly should be initiated.

\section{Cushing's Syndrome}

Individuals with uncontrolled Cushing's syndrome of any origin are at higher risk of infection in general. ${ }^{63}$ If experiencing fever or cough supportive treatment should be initiated. In case of shortness of breath, hospital admission should be advised.

\section{Thyroid Disease}

In COVID-19 patients admitted in hospital, routine thyroid function tests are not recommended. There is no benefit of levothyroxine treatment in patients with euthyroid syndrome. ${ }^{65}$ Patients with thyrotoxicosis should continue taking medications as prescribed as those with uncontrolled thyrotoxicosis may be at higher risk of complications (such as thyroid storm) from any infection. Patients on corticosteroids or immunosuppressive agents for thyroid eye disease are more susceptible and are at high risk of severe illness from COVID-19 and such patients need to take more precautions. ${ }^{66}$ Carbimazole induced agranulocytosis and subacute thyroiditis should be kept in mind as 
differentials in patients presenting with sore throat. According to recent case reports, COVID-19 infection may cause subacute thyroiditis. Hypothyroidism patients should continue taking levothyroxine treatment as suggested. ${ }^{66}$

\section{Bone and Mineral Metabolism (Osteoporosis)}

While there is no evidence of increased risk of COVID-19 to patients with bone and mineral metabolism disorders, the unprecedented global lockdowns have significantly affected their care. It is advisable for those on medications such as denosumab and romosozumab to receive timely infusions, however, infusions of bisphosphonates such as Zoledronic acid may be deferred due to their long half-life. ${ }^{67}$

\section{Sodium Metabolism (Diabetes Insipidus)}

Central and nephrogenic diabetes insipidus (DI) pose a particular challenge due to reduced availability of laboratory (electrolyte) testing. An opinion piece recently highlighted this challenge, encouraging the practice of once a week aquaresis by omitting one dose of vasopressin in individuals with existing DI. ${ }^{68}$

\section{Conclusion}

The fight against COVID-19 has been proven to be a challenging one. As in every war, it's the duty of the frontline fighters to protect the vulnerable group with utmost preference - the elderly and those with comorbid conditions. Therefore, all healthcare personnel should make the best use of updated knowledge and skills to ensure adequate protective measures and timely treatment for COVID-19 patients having diabetes, other endocrine diseases or any other comorbidities.

\section{Disclosure}

The authors report no conflicts of interest in this work.

\section{References}

1. Chen Y, Gong X, Wang L, Guo J. Effects of hypertension, diabetes and coronary heart disease on COVID-19 diseases severity: a systematic review and meta-analysis. medRxiv. 2020.

2. Bornstein SR, Rubino F, Khunti K, et al. Practical recommendations for the management of diabetes in patients with COVID-19. Lancet Diabetes Endocrinol. 2020;8(6):546-550. doi:10.1016/S2213-8587(20)30152-2

3. Latif ZA, Ashrafuzzaman SM, Amin MF, Gadekar A, Sobhan MJ, Haider T. A cross-sectional Study to evaluate diabetes management, control and complications in patients with type 2 diabetes in Bangladesh. BIRDEM Med J. 2017;7(1):17-27. doi:10.3329/birdem. v7i1.31268
4. Remuzzi A, Remuzzi G. COVID-19 and Italy: what next? Lancet. 2020;395(10231):1225-1228. doi:10.1016/S0140-6736(20)30627-9

5. Barrera FJ, Shekhar S, Wurth R, et al. Prevalence of diabetes and hypertension and their associated risks for poor outcomes in Covid-19 patients. J Endocr Soc. 2020;4(9):bvaa102. doi:10.1210/ jendso/bvaa102

6. Roncon L, Zuin M, Rigatelli G, Zuliani G. Diabetic patients with COVID-19 infection are at higher risk of ICU admission and poor short-term outcome. J Clin Virol. 2020;127:104354. doi:10.1016/j. jev.2020.104354

7. Report of the WHO-China Joint Mission on Coronavirus Disease 2019 (COVID-19). World Health Organization; 2020. Available from: https://www.who.int/publications/i/item/report-of-the-whochina-joint-mission-on-coronavirus-disease-2019-(covid-19).

Accessed June 212020.

8. The Novel Coronavirus Pneumonia Emergency Response Epidemiology Team. The epidemiological characteristics of an outbreak of 2019 novel coronavirus diseases (COVID-19)-China, 2020. China CDC Weekly. 2020;2(8):113-122. doi:10.46234/ccdcw2020.032

9. Zhang B, Zhou X, Qiu Y, et al. Clinical Characteristics of 82 Death Cases with COVID-19. medRxiv. 2020.

10. Alshaikh A, Alsifri S, Alhozali A, et al. Saudi Scientific Diabetes Society Position Statement: management of diabetes mellitus in the pandemic of COVID-19. Int J Clin Med. 2020;11(05):199-206. doi:10.4236/ijcm.2020.115020

11. Gupta R, Hussain A, Misra A. Diabetes and COVID-19: evidence, current status and unanswered research questions. Eur J Clin Nutr. 2020;74(6):864-870. doi:10.1038/s41430-020-0652-1

12. Guo W, Li M, Dong Y, et al. Diabetes is a risk factor for the progression and prognosis of COVID-19. Diabetes Metab Res Rev. 2020; 3319

13. Hoffmann M, Kleine-Weber H, Schroeder S, et al. SARS-CoV-2 cell entry depends on ACE2 and TMPRSS2 and is blocked by a clinically proven protease inhibitor. Cell. 2020;181(2):271-280. doi:10.1016/j. cell.2020.02.052

14. Bindom SM, Lazartigues E. The sweeter side of ACE2: physiological evidence for a role in diabetes. Mol Cell Endocrinol. 2009;302 (2):193-202. doi:10.1016/j.mce.2008.09.020

15. Roca-Ho H, Riera M, Palau V, Pascual J, Soler MJ. Characterization of ACE and ACE2 expression within different organs of the NOD mouse. Int J Mol Sci. 2017;18(3):e563. doi:10.3390/ijms 18030563

16. Yang JK, Lin SS, Ji XJ, Guo LM. Binding of SARS coronavirus to its receptor damages islets and causes acute diabetes. Acta Diabetol. 2010;47(3):193-199. doi:10.1007/s00592-009-0109-4

17. American Diabetes Association. 6. Glycemic targets: standards of medical care in diabetes-2020. Diabetes Care. 2020;43(Suppl. 1): S66-S76. doi: 10.2337/dc20-S006

18. Cemiyeti TD. Expert recommendation on glucose management strategies of diabetes combine with COVID-19. J Clin Intern Med. 2020;37(3):215-219.

19. Banerjee M, Chakraborty S, Pal R. Diabetes self-management amid COVID-19 pandemic. Diabetes Metab Syndr. 2020;14(4):351-354. doi:10.1016/j.dsx.2020.04.013

20. Basu A, Slama MQ, Nicholson WT, et al. Continuous glucose monitor interference with commonly prescribed medications: a pilot study. J Diabetes Sci Technol. 2017;11(5):936e41. doi:10.1177/1932296817697329

21. Rao PV, Makkar BM, Kumar A, et al. RSSDI consensus on self-monitoring of blood glucose in types 1 and 2 diabetes mellitus in India. Int $J$ Diabetes Dev Ctries. 2018;38(3):260-279. doi:10.1007/s13410-018-0677-3

22. Schuster KM, Barre K, Inzucchi SE, et al. Continuous glucose monitoring in the surgical intensive care unit: concordance with capillary glucose. J Trauma Acute Care Surg. 2014;76(3):798e803. doi:10.1097/TA.0000000000000127 
23. Wang A, Zhao W, Xu Z, Gu J. Timely blood glucose management for the outbreak of 2019 novel coronavirus disease (COVID-19) is urgently needed. Diabetes Res Clin Pract. 2020;162:108118. doi:10.1016/j.diabres.2020.108118

24. Sick day rules: how to manage Type 2 diabetes if you become unwell with coronavirus and what to do with your medication. London: NHS; 2020. Available from: https:/www.england.nhs.uk/london/wp-content/uploads/ sites/8/2020/04/3.-Covid-19-Type-2-Sick-Day-Rules-Crib-Sheet -06042020.pdf. Accessed June 22, 2020.

25. Matthews R Medscape diabetes and endocrinology, glucose control key with COVID-19 in diabetes; 2020. Available from: https://www medscape.com/viewarticle/927044\#vp 2. Accessed March 8, 2020.

26. Barazzoni R, Bischoff SC, Krznaric Z, Pirlich M, Singer P. ESPEN expert statements and practical guidance for nutritional management of individuals with sars-cov-2 infection. Clin Nutr. 2020;39:1631-1638. doi:10.1016/j.clnu.2020.03.022

27. Vitamin D deficiency in Ireland-implications for COVID-19: results from the Irish Longitudinal Study on Ageing (TILDA). Dublin: Irish Longitudinal Study on Ageing (TILDA); 2020. Available from: https://ilda.tcd.ie/publications/reports/pdf/Report_Covid19VitaminD. pdf. Accessed February 07, 2021.

28. Ghaffari H, Tavakoli A, Moradi A, et al. Inhibition of H1N1 influenza virus infection by zinc oxide nanoparticles: another emerging application of nanomedicine. J Biomed Sci. 2019;26(1):70. doi:10.1186/s12929-019-0563-4

29. Hemilä H. Vitamin C intake and susceptibility to pneumonia. Pediatr Infect Dis J. 1997;16(9):836-837. doi:10.1097/00006454199709000-00003

30. Covid 19 and diabetes. International Diabetes Federation; 2020. Available from: https://www.idf.org/aboutdiabetes/what-is-diabetes/covid-19-anddiabetes/1-covid-19-and-diabetes. Accessed February 07, 2021.

31. Ghelichkhani P, Esmaeili M. Prone Position in Management of COVID-19 Patients; a Commentary. Arch Acad Emerg Med. 2020;8 (1):e48.

32. Thomas P, Baldwin C, Bissett B, et al. Physiotherapy management for COVID-19 in the acute hospital setting: clinical practice recommendations. J Physiother. 2020;66(2):73-82. doi:10.1016/j. jphys.2020.03.011

33. National Guidelines on Clinical Management of COVID-19. Version 8.0. Dhaka: Directorate General of Health Services; 2020. Available from: https://dghs.gov.bd/images/docs/Guideline/COVID_Guideline_ v8_2.pdf. Accessed November 30, 2020.

34. Covid-19 and Diabetes: BADAS guide for healthcare professionals. Dhaka: Diabetic Association of Bangladesh; 2020. Available from: https://drive.google.com/open?id=1F2hHB1IMjeXKHcyHYnvHuqYzoj00Xnj. Accessed September 30, 2020.

35. Advice for healthcare professionals on coronavirus (Covid-19) and diabetes. Leicester: Leicester Diabetes Centre, Diabetes UK; 2020. Available from: https://www.diabetes.org.uk/professionals/resources/ coronavirus-clinical-guidance\#guidance-care-homes. Accessed September 30, 2020.

36. Mental health and psychosocial considerations during the COVID-19 outbreak.World Health Organization; 2020. Available from: https:// www.who.int/publications/i/item/WHO-2019-nCoV-MentalHealth2020.1. Accessed 23 Mar 2020.

37. COVID-19 outbreak: guidance for people with diabetes. International Diabetes Federation; 2020. Available from: https:/www.idf.org/ournetwork/regions-members/europe/europe-news/196-information-oncorona-virus-disease-2019-covid-19-outbreak-and-guidance-for-people -with-diabetes.html. Accessed October 022020.

38. Zhou G, Myers R, Li Y, et al. Role of AMP-activated protein kinase in mechanism of metformin action. J Clin Invest. 2001;108 (8):1167-1174. doi:10.1172/JCI13505
39. Plattner F, Bibb JA. Serine and threonine phosphorylation. In: Brady ST, Siegel GJ, Albers RW, Price DL, editors. Basic Neurochemistry (Eighth Edition). New York: Academic Press; 2012:467-492. doi:10.1016/B978-0-12-374947-5.00025-0

40. Sharma S, Ray A, Sadasivam B. Metformin in COVID-19: a possible role beyond diabetes. Diabetes Res Clin Pract. 2020;164:108183. doi:10.1016/j.diabres.2020.108183

41. Singh AK, Khunti K. Assessment of risk, severity, mortality, glycemic control and antidiabetic agents in patients with diabetes and COVID-19: a narrative review. Diabetes Res Clin Pract. 2020;165:108266. doi:10.1016/j.diabres.2020.108266

42. Singh AK, Singh R, Saboo B, Misra A. Non-insulin anti-diabetic agents in patients with type 2 diabetes and COVID-19: a critical appraisal of literature. Diabetes Metab Syndr. 2020;15(1):159-167. doi:10.1016/j.dsx.2020.12.026

43. Gordon DE, Jang GM, Bouhaddou M, et al. A SARS-CoV-2-human protein-protein interaction map reveals drug targets and potential drug- repurposing. Nature. 2020;583(7816):459-468. doi:10.1038/ s41586-020-2286-9

44. Iacobellis G. COVID-19 and diabetes: can DPP4 inhibition play a role? Diabetes Res Clin Pract. 2020;162:108-125. doi:10.1016/j. diabres.2020.108125

45. Yang W, Cai X, Han X, Ji L. DPP-4 inhibitors and risk of infections: a meta-analysis of randomized controlled trials. Diabetes Metab Res Rev. 2016;32(4):391-404. doi:10.1002/dmrr.2723

46. Singh A, Singh R. Dipeptidyl-peptidase- 4 inhibitors in type 2 diabetes and COVID-19: from a potential repurposed agent to a useful treatment option. J Diabetol. 2020;11(3):131-136. doi:10.4103/JOD.JOD_53_20

47. Pal R, Bhadada S. Should anti-diabetic medications be reconsidered amid COVID-19 pandemic? Diabetes Res Clin Pract. 2020;108146. doi:10.1016/j.diabres.2020.108146

48. Ceriello A, Stoian AP, Rizzo M. COVID-19 and diabetes management: what should be considered? Diabetes Res Clin Pract. 2020;163:108151. doi:10.1016/j.diabres.2020.108151

49. Drucker DJ. Coronavirus infections and type 2 diabetes-shared pathways with therapeutic implications. Endocr Rev. 2020;41(3):bnaa011. doi:10.1210/endrev/bnaa011

50. Amin EF, Rifaai RA, Abdel-Latif RG. Empagliflozin attenuates transient cerebral ischemia/reperfusion injury in hyperglycemic rats via repressing oxidative-inflammatory-apoptotic pathway. Fundam Clin Pharmacol. 2020;34(5):548-558. PMID: 32068294. doi:10.1111/ fcp. 12548

51. Ceriello A. Thiazolidinediones as anti-inflammatory and anti-atherogenic agents. Diabetes Metab Res Rev. 2008;24(1):14-26. doi:10.1002/dmrr.790

52. Zhou F, Yu T, Du R, Fan G, Liu Y, Liu Z. Clinical course and risk factors for mortality of adult inpatients with COVID-19 in Wuhan, China: a retrospective cohort study. Lancet. 2020;395 (10229):1054-1062. doi:10.1016/S0140-6736(20)30566-3

53. Singh AK, Gillies CL, Singh R, et al. Prevalence of co-morbidities and their association with mortality in patients with COVID-19: a systematic review and meta-analysis. Diabetes Obes Metab. 2020;22(10):1915-1924. doi:10.1111/dom.14124

54. Diabetes management during the coronavirus pandemic: be proactive and prepared. Melbourne: Royal Australian College of General Practitioners; 2020. Available from: https://www.racgp.org.au/getme dia/97a5abb4-1290-42cb-91c0-eabcaa8ca590/Diabetes-managementduring-coronavirus-pandemic_1.pdf.aspx. Accessed February 16, 2021.

55. Ceriello A, Standl E, Catrinoiu D, et al.; Diabetes and Cardiovascular Disease (D\&CVD) EASD Study Group. Issues of cardiovascular risk management in people with diabetes in the COVID-19 era. Diabetes Care. 2020;43(7):1427-1432. doi:10.2337/dc20-0941 
56. Bangladesh Endocrine Society Insulin Guideline 2018. Dhaka: Bangladesh Endocrine Society; 2018. Available from: http://bes-org. net/wp-content/uploads/2019/03/Insulin\%20Guideline.pdf. Accessed June 212020.

57. American Diabetes Association. Comprehensive Medical Evaluation and Assessment of Comorbidities: standards of Medical Care in Diabetes-2021. Diabetes Care. 2021;44(Suppl. 1):S40-S52. doi: $10.2337 / \mathrm{dc} 21-\mathrm{S} 004$

58. National Inpatient Diabetes Covid-19 Response Group. COncise adVice on Inpatient Diabetes (COVID: Diabetes): guidance For Managing Inpatient Hyperglycaemia. Leicester: Leicester Diabetes Centre, Diabetes UK; 2020. Available from: https:/www.diabetes. org.uk/resources-s3/public/2020-04/COvID_Hyper_v4.1.pdf. Accessed February 18, 2021.

59. Rayman G, Lumb A, Kennon B, et al. London Inpatient Diabetes Network-COVID-19. Guidelines for the management of diabetes services and patients during the COVID-19 pandemic. Diabet Med. 2020;37(7):1087-1089. doi:10.1111/dme.14316

60. Guidance for maternal medicine in the evolving coronavirus (COVID-19) pandemic: information for healthcare professionals, Version 2.4. London: Royal college of obstetrics and gynecologists; 2020. Available from: https://www.rcog.org.uk/globalassets/docu ments/guidelines/2020-07-10-guidance-for-maternal-medicine.pdf. Accessed February 20, 2021.

61. Yamamoto JM, Donovan LE, Feig DS, Berger H. Urgent updatetemporary alternative screening strategy for gestational diabetes screening during the COVID-19 Pandemic: a Joint Consensus Statement from the Diabetes Canada Clinical Practice Guidelines Steering Committee and the Society of Obstetricians and Gynecologists of Canada. Available from: https:/www.sogc.org/common/Uploaded\%20files/GDM-COVID $-19 \% 20$ temporary $\% 20$ screening $\% 20$ guidelines $\% 20-\% 2020200402 \%$ 20Agreed\%20Final.pdf. Accessed March 04, 2021.

62. Interim U.S. Guidance for Risk Assessment and Work Restrictions for Healthcare Personnel with Potential Exposure to SARS-CoV-2. Washington: Center for Disease Control; 2021. Available from: https://www.cdc.gov/coronavirus/2019-ncov/hcp/guidance-riskassesment-hcp.html. Accessed March 05, 2021.
63. AACE position statement: coronavirus (COVID-19) and people with adrenal insufficiency and cushing's syndrome. USA: American Association of Clinical Endocrinologists; 2020. Available from: https://pro.aace.com/recent-news-and-updates/aace-positionstatement-coronavirus-covid-19-and-people-adrenal. Accessed March $05,2021$.

64. COVID-19 and endocrine diseases, A statement from the European Society of Endocrinology. Bristol: European Society of Endocrinology; 2021. Available from: https://www.ese-hormones. org/media/2223/covid-and-endocrine-diseases-ese-statementfinal_23032020.pdf. Accessed March 062021.

65. Rajput R, Agarwal A, Ganie MA, et al. Coronavirus disease 2019 and thyroid disease: position statement of Indian Thyroid Society. Thyroid Res Pract. 2020;17(1):4-6. doi:10.4103/trp.trp_28_20

66. AACE position statement: Coronavirus (COVID-19) and people with thyroid disease [homepage on the internet]. USA: American Association of Clinical Endocrinologists; 2020. Available from: https://pro.aace.com/recent-news-and-updates/aace-positionstatement-coronavirus-covid-19-and-people-thyroid-disease. Accessed February 26, 2021.

67. Foundation NO patients and providers fact sheet: injections or infusions of osteoporosis medications during the COVID-19 Pandemic cdn.nof.org2020. Arlington: National Osteoporosis Foundation; 2020. Available from: https://cdn.nof.org/wp-content/uploads/NOFCOVID-Factsheet_pdf. Accessed March 06, 2021.

68. Liamis G, Milionis HJ, Elisaf M. Hyponatremia in patients with infectious diseases. $J$ Infect. 2011;63(5):327-335. doi:10.1016/j. jinf.2011.07.013

\section{Publish your work in this journal}

Diabetes, Metabolic Syndrome and Obesity: Targets and Therapy is an international, peer-reviewed open-access journal committed to the rapid publication of the latest laboratory and clinical findings in the fields of diabetes, metabolic syndrome and obesity research. Original research, review, case reports, hypothesis formation, expert opinion and commentaries are all considered for publication. The manuscript management system is completely online and includes a very quick and fair peer-review system, which is all easy to use. Visit http://www.dovepress.com/testimonials.php to read real quotes from published authors. 